\title{
Bajo la Mirada de Cangjie*: Lengua y Escritura China en la Ciudad de Buenos Aires
}

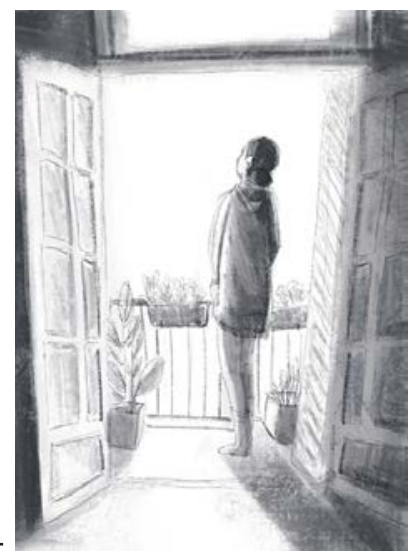

María Florencia Sartori

Universidad de Buenos Aires, Argentina

sartori.florencia@gmail.com

Trabajo recibido el 4 de abril de 2019 y aprobado el 30 de mayo de 2019.

\section{Resumen}

A pesar de la distancia geográfica y cultural entre China y Argentina, son cada vez más frecuentes los intercambios entre estos dos países. Además, en los últimos quince años la inmigración desde este país asiático se incrementó considerablemente. En este trabajo nos enfocaremos en realizar un acercamiento al paisaje lingüístico de la CABA tomando como eje la utilización de la escritura china, en sus dos variedades (tradicional y simplificada) en el espacio público. Nos centraremos especialmente en el análisis del paisaje lingüístico del Barrio Chino de la CABA ya que es en este espacio público en el que se pueden observar distintos agentes: los inmigrantes chinos y taiwaneses, el Estado municipal y el Estado Nacional Chino. La utilización de la escritura tradicional o la simplificada dentro del Barrio Chino indica no solo dos momentos de inmigración sino también una tensión política entre aquellos provenientes de la RPC y aquellos que son originarios de Taiwán. El GCBA, por su parte, elige la escritura simplificada para realizar la señalética del Barrio, tomando de esta manera una posición también política respecto de cuál es la escritura asociada a los "chinos". Asimismo, esta intervención sobre el espacio público utiliza la escritura no con un fin instrumental sino para construir un escenario en el cual la "cultura china" es ofrecida al "turista".

\section{Under the gaze of Cangjie: Chinese Language and writing in the City of Buenos Aires}

\footnotetext{
Abstract

Despite the geographical and cultural distance between China and Argentina, cultural and economic exchanges between these two countries are increasingly frequent. In addition, in the last fifteen years immigration

Keywords

Chinese writing Buenos Aires ChinaTown Migrants
Palabras clave Escritura china Buenos Aires Barrio Chino Inmigrantes 
from this Asian country had increased considerably. In this article we will make an approach to the linguistic landscape of the CABA, considering specially the use of Chinese writing, in its two varieties (traditional and simplified) in the public space. We will focus on the linguistic landscape of the Chinatown of the CABA since it is in this public space where different agents can be observed: the Chinese and Taiwanese immigrants, the municipal State and the Chinese National State. The use of traditional or simplified writing within the Chinatown indicates not only two moments of immigration but also a political tension between those from the PRC and those who are originally from Taiwan. The GCBA, on the other hand, chooses the simplified writing to carry out the signage of the Neighborhood, taking a political position regarding what is the writing associated with the "Chinese". Likewise, this intervention on public space uses writing not for an instrumental purpose but to construct a scenario in which "Chinese culture" is offered to the "tourist".

\section{Sob o olhar de Cangjie: Língua e Escrita Chinesa na Cidade de Buenos Aires}

\section{Resumo}

Apesar da distância geográfica e cultural entre a China e a Argentina, as trocas entre esses dois países são cada vez mais frequentes. Além disso, nos últimos quinze anos, a imigração deste país asiático aumentou consideravelmente. Neste trabalho vamos nos concentrar em fazer uma abordagem ao panorama linguístico da CABA tomando como eixo o uso da escrita chinesa, em suas duas variedades (tradicional e simplificada) no espaço público. Vamos nos concentrar principalmente na análise da paisagem linguística da CABA Chinatown, pois é nesse espaço público onde você pode ver diferentes agentes: imigrantes chineses e de Taiwan, o governo municipal e do Governo Nacional chinês. O uso de escrita tradicional ou simplificada dentro da Chinatown indica não apenas dois momentos de imigração, mas também uma tensão política entre os da República Popular da China e aqueles que são originalmente de Taiwan. O GCBA, por outro lado, escolhe a redação simplificada para realizar a sinalização do Bairro, tomando assim uma posição política sobre o que é a escrita associada aos "chineses". Da mesma forma, essa intervenção no espaço público utiliza a escrita não para fins instrumentais, mas para construir um cenário no qual a "cultura chinesa" seja oferecida ao "turista".

\section{Introducción}

China está en las antípodas de Argentina, su lengua es muy diferente al español, su escritura no se rige por un principio fonemográfico sino por uno morfologográfico (Rovira Esteva 2010). Decir "chino básico", en nuestro país, es equivalente a decir que es demasiado difícil para nuestro entendimiento, "ser un chino" se utiliza en Buenos Aires cuando un plan es muy complicado de ser llevado a cabo. A pesar de esta distancia, geográfica y cultural, son cada vez más frecuentes las referencias a la República Popular China (RPC, en adelante) en los medios de comunicación y, también, cada vez más personas eligen estudiar la lengua oficial de este Estado.

\section{Palavras-chave}

Escrita chinesa Buenos Aires Chinatown imigrantes 
En este artículo nos proponemos estudiar la presencia de las escrituras chinas en el Barrio Chino de la Ciudad Autónoma de Buenos Aires y su incidencia en la conformación del paisaje lingüístico. Entendemos que este último debe ser analizado en su vinculación con los procesos migratorios que construyeron una sociedad multilingüe y también con las políticas lingüísticas del Estado y con las acciones que los migrantes realizan en relación con sus lenguas y escrituras. En este sentido, seguimos a Srhir (2013) quien sostiene que los actores sociales implicados en las dinámicas sociolingüísticas —instituciones públicas, individuos y asociaciones, por mencionar algunos ejemplos - tienen un rol muy importante en la conformación del paisaje lingüístico. Tal como mostraremos en este artículo la relación entre estos actores no siempre es armónica y, a causa de esto, se pueden observar tensiones y diferencias en el espacio público analizado.

En este artículo entendemos, junto con Shohamy (2015), que los estudios del paisaje lingüístico pueden contribuir a profundizar la comprensión de la política lingüística de un Estado. Este es uno de los actores que modifica el espacio público no solo regulando qué puede y qué no puede ser escrito en él sino también a través de intervenciones explícitas, por ejemplo, a través de la señalética (como analizaremos en este artículo). Asimismo, estos estudios permiten comprender y dimensionar el peso de otros agentes de la política lingüística no estatales. Shohamy (2006, referida en Shohamy 2015) propone que el paisaje lingüístico es un mecanismo que permite crear una política lingüística "de facto". En este sentido, el estudio del paisaje lingüístico permite dar cuenta también de esos otros modos de circulación de las lenguas y sus escrituras que no están necesariamente reguladas, aunque sí permitidas, por el Estado.

La política lingüística de la CABA para la enseñanza del chino permite reconocer tres agentes: los inmigrantes, el Estado municipal y el Estado chino. El "Instituto Cultural SinHeng"1 y la Asociación Cultural Chino Argentina son instituciones privadas impulsadas por inmigrantes taiwaneses en Argentina. También como parte de estas iniciativas, se emitió un programa televisivo, “Chino Básico” (los domingos a las 14.30 en el canal Metro), que enseñaba la lengua y la cultura china. Este programa fue producido por la Fundación Muralla Dorada, coorganizadora, junto con el Gobierno de la Ciudad de Buenos Aires (GCBA, en adelante), de los festejos de Año Nuevo desde el año 2015 (Laborde 2017). Esta fundación está compuesta por inmigrantes de la RPC y tiene vínculos tanto con el Gobierno municipal como con la Embajada de la RPC en Argentina. Las iniciativas gubernamentales, por su parte, son desarrolladas por el Gobierno de la Ciudad de Buenos Aires, el Gobierno de la RPC y algunas universidades nacionales. El Gobierno de la Ciudad de Buenos Aires enseña idioma chino a través de "Lenguas en los Barrios". Este programa gratuito dicta también clases de inglés, francés, alemán, portugués, italiano y árabe. La Universidad de Buenos Aires ofrece cursos de esta lengua en el Laboratorio de Idiomas de la Facultad de Filosofía y Letras ${ }^{2}$. El Gobierno de la República Popular China, por su parte, organiza los cursos de chino a través del Instituto Confucio, que depende del Ministerio de Educación de la República Popular China. Estos tres agentes de política lingüística se solapan en el ámbito de la Ciudad. Es interesante, aunque no será desarrollado en este trabajo, la existencia de tensiones respecto de qué escritura enseñar entre los inmigrantes taiwaneses y los chinos discusión que no está presente en los otros agentes de política que reconocimos. La razón por la que esta discusión desaparece, entendemos, es clara: la asociación de la lengua con un Estado
1. Este instituto comenzó enseñando chino a descendientes de migrantes. Si bien ahora sumó la enseñanza a hispanoparlantes, continúa enseñando a hijos de chinos y taiwaneses. Según afirman en su página web lo hacen para que "las próximas generaciones no perdieran el chino como lengua materna".

2. La Universidad Nacional de San Martín también dicta cursos de idioma chino, arancelados y abiertos al público en general, pero se dictan fuera del ámbito de la Ciudad Autónoma de Buenos Aires. 
especialmente, la RPC. Tras visitar una escuela primaria en la que se enseña chino y español, el entonces Jefe de Gobierno de la Ciudad Autónoma de Buenos Aires, Mauricio Macri, publicó en su página de Facebook un mensaje en el cual afirmaba lo siguiente: "En el pasado se aprendía francés para leer literatura e inglés para hacer negocios ¿Cuál será la lengua del futuro? Tal vez el chino". Entendemos que es esta representación sociolingüística, el chino como "lengua del futuro", que necesariamente se relaciona con la posición geopolítica de la RPC, la que motiva que en la Ciudad de Buenos Aires en los últimos años haya crecido tanto la oferta como la demanda de cursos de lengua.

En este artículo en particular partimos de la hipótesis de que son los mismos agentes de política lingüística que se relacionan con la enseñanza del chino en la CABA los que pueden reconocerse en el análisis del paisaje lingüístico del Barrio Chino. Tal como plantea Shohamy (2015), sostenemos que las intervenciones sobre el espacio público pueden ser realizadas tanto por instituciones con autoridad como por distintos grupos ${ }^{3}$. La autora también refiere a la distinta legitimidad que pueden tener unos y otros; en este artículo nos preguntaremos en este sentido si la legitimidad deviene necesariamente del poder político dentro del Estado.

En este trabajo nos enfocaremos en, por un lado, realizar un acercamiento al paisaje lingüístico de la CABA tomando como eje la utilización de la escritura china, en sus dos variedades (tradicional y simplificada ${ }^{4}$ ) en el espacio público; y, por el otro, en explicar este paisaje en relación con las oleadas migratorias y con la intervención de los Estados (municipal, nacional argentino y nacional RPC). Para ello nos centraremos especialmente en el análisis del paisaje lingüístico del Barrio Chino de la CABA. Shohamy (2015) afirma que es necesario no solo examinar el paisaje lingüístico en los estados o en ciudades en su totalidad sino acercarse a pequeñas porciones, ya que es ahí donde se pueden ver las reacciones, si las hubiera, a las políticas que provienen del Estado. Al mismo tiempo analizar pequeños espacios nos permite dar cuenta de la heterogeneidad existente en el espacio urbano. En este sentido, el Barrio Chino constituye un espacio en el cual se pueden ver las tensiones entre los migrantes y entre los migrantes y los estados.

A modo de contextualización, ya que permite entender no solo el multilingüismo de la CABA sino también las distintas intervenciones sobre el espacio público que realizan los inmigrantes, comenzaremos este artículo haciendo una breve reseña de las migraciones chinas a Argentina.

\section{Migración desde la RPC a Argentina}

Si bien hay registros de migración desde China a Argentina desde finales del siglo XIX, se intensificó a partir de los años cincuenta del siglo pasado. Según Denardi (2016), fue recién en la década de los setenta y ochenta que se produjo un ingreso masivo de migrantes provenientes de Taiwán y no fue hasta los noventa que empezaron a llegar desde la República Popular China. Sin embargo, la mayor cantidad de migrantes desde este lugar empezó a llegar después del año 2004. Según datos del último Censo Nacional de Población realizado por el Instituto Nacional de Estadísticas y Censos en el año 2010, la población total nacida en "China” que vivía en Argentina era de 8929 personas, de las cuales 3932 vivían en la Ciudad Autónoma de
3. La autora utiliza el término "comunidades" que, en este trabajo, preferimos no utilizar ya que los límites entre las comunidades son siempre difusos y, entendemos, impuestos desde afuera. Por ejemplo, en el caso que nos ocupa pensar en la existencia de una única comunidad china implicaría reducir la diversidad interna, aún cuando sea claro que no estamos incluyendo a los taiwaneses. Además, es parte del discurso del GCBA denominar a estos migrantes como parte de la "comunidad" china y, en general, bajo esta denominación incluyen tanto a inmigrantes desde la RPC como desde Taiwán.

4. En la República Popular China a partir del año 1949 se llevó a cabo un proceso de planificación lingüística que incluyó entre sus medidas la simplificación de la escritura. El proceso de simplificación hizo que en algunos casos se reemplazara el carácter por una variante más popular: 個 se convirtió en 个, 網 en网; otros fueron simplificados eliminando trazos a un carácter existente: de習se seleccionó uno de los dos elementos superiores y entonces se usa 习 para denotar el mismo sentido; un tercer procedimiento fue reemplazar un carácter por un homófono, este procedimiento permitió reducir el número total de sinogramas: entonces, a partir de la simplificación tanto 䘽 como 后 se escriben 后; 隻 y 祇 se escriben 只 (Lien Tan-Pan 2005). Además de la simplificación, en 1957 se occidentalizó el sentido de la lectura y la escritura, es decir, se empezó a escribir de izquierda a derecha. Estos procesos no se dieron en Taiwán, por lo tanto, los inmigrantes que provienen de esta isla escriben y enseñan la escritura tradicional. Para un análisis detallado de este tema, ver Rohsenow, J. (2004). 
Buenos Aires (CABA). Estas cifras, si bien oficiales, no se condicen con lo que algunos representantes de la comunidad dicen: Denardi (2016) afirma que hay referentes comunitarios con que ella se entrevistó que sostienen que en Argentina hay 12.000 taiwaneses, 200.000 chinos registrados y 100.000 más no registrados.

Respecto del año de llegada al país, el último censo muestra diferentes patrones de migración entre el total nacional y el de CABA: mientras que en el primer caso se ve un aumento porcentual, el segundo muestra un leve descenso. Así, para el total del país encontramos que el 12,4\% de los que vivían en Argentina en 2010 llegó antes de 1991, el 38,8 \% lo hizo entre 1991 y 2001 y el 48,8\%, entre 2002 y 2011; por el contrario, en la CABA el 17\% llegó a Argentina antes de 1991, el 42,8\% llegó entre 1991 y 2001 y el $40,2 \%$ a partir de 2002. Este descenso puede ser interpretado teniendo en cuenta que los primeros migrantes de la última oleada migratoria de China hacia Argentina se localizaron en CABA, donde era más fácil establecerse y emprender actividades económicas, mientras que los que vinieron después, tomando como base lo hecho por los primeros, se establecieron en otras zonas de la Argentina. Los medios argentinos en el año 2011 daban cuenta de este movimiento de estos migrantes y, en particular, de la apertura de supermercados en el interior del país como consecuencia de haber alcanzado un "techo en la Capital Federal" (Manzoni 2011, versión digital).

El censo del año 2010 distingue entre nacidos en China y nacidos en Taiwán. La pregunta de la cédula censal no les daba opciones a los encuestados, sino que los sujetos debían informar en qué país habían nacido. Por lo tanto, esta distinción emerge no de la confección del censo sino de las respuestas aportadas. El número de personas nacidas en Taiwán que fue censada en 2010 es de 2875, de las cuales 1727 vivían en la CABA. De estas últimas, solo el 6,9\% llegó a Argentina después de 2002 y el 55,6\% llegó antes de 1991. Esta diferenciación en el censo es importante porque muestra que en Argentina la distinción China-Taiwán es relevante para los migrantes. No sabemos si fue la mayor migración de ciudadanos de la RPC la que motivó la necesidad de que apareciera esta distinción en este censo y no en los anteriores. En el apartado siguiente, al analizar el paisaje lingüístico del Barrio Chino, nos referiremos a estas dos migraciones y cómo uno y otro grupo intervienen en el espacio público, enfocando especialmente en la distinción entre la escritura tradicional y la simplificada.

El perfil socioeconómico y cultural es muy diverso: hay residentes chinos en Argentina que terminaron el colegio secundario y otros que tienen estudios de posgrado. Muchos migrantes y descendientes de migrantes se dedican a la enseñanza del chino, ya sea en las escuelas comunitarias, ya en el Instituto Confucio o de manera particular. Algunos de ellos han estudiado carreras universitarias en nuestro país -aquellos que migraron hace mayor cantidad de años-y otros tienen títulos universitarios de su país de origen. La actividad económica más visible que realizan los inmigrantes chinos en la CABA es la comercial: restaurantes de tenedor libre, locales de venta de comida por peso, regalerías y, principalmente, los llamados "supermercados chinos" (Delmonte, Denardi y Sartori 2018). En los últimos quince años creció el número de empleados expatriados de compañías chinas con filiales en Argentina. Entre ellos se pueden encontrar ingenieros, traductores y abogados. No hay cifras oficiales de cuántos son: Conconi y Soffieto (2015) afirman que son casi mil. El salario de estos gerentes les permite 
vivir cómodamente en Buenos Aires y, en el caso de los cargos jerárquicos, los gastos de alquiler, en general en Puerto Madero, y viáticos los cubre la empresa para la que trabajan.

Una particularidad de esta migración es que no está localizada geográficamente en una zona en particular de la Ciudad. Según el Censo Nacional de Población 2010, los migrantes chinos viven en todas las comunas de la CABA. La mayoría se localiza en la comuna 3 (San Cristóbal y Balvanera), y la minoría, en la comuna 8 (Villa Soldati y Villa Riachuelo).

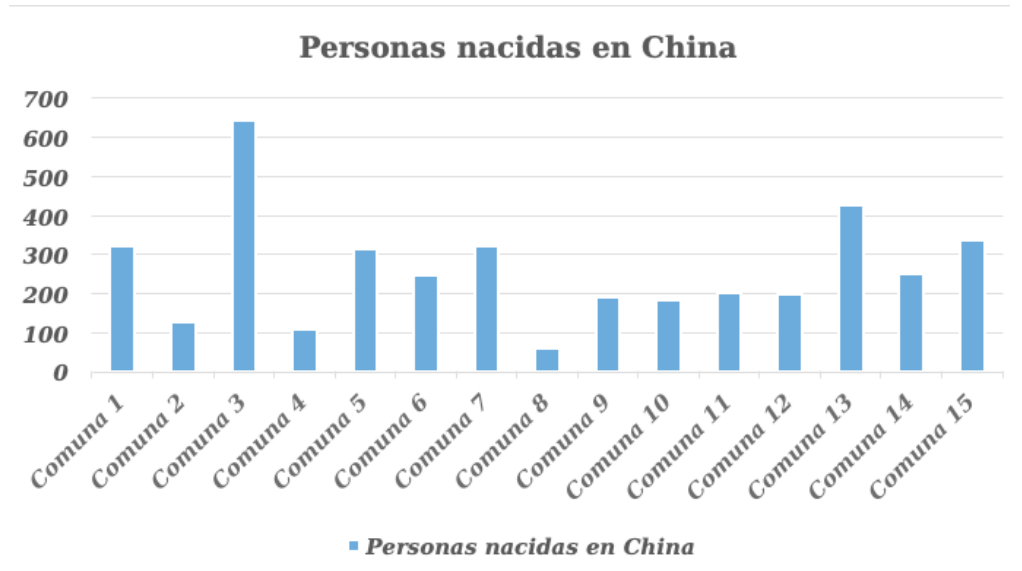

Gráfico 01. Población por comuna (elaboración propia a partir de INDEC, 2010).

El Barrio Chino, al que nos referiremos especialmente en el apartado siguiente se ubica en la comuna 13, la segunda con más inmigrantes chinos según el Censo Nacional de Población.

\section{Presencia de la escritura china en la CABA}

En este apartado, mostraremos el modo en que la escritura china, en sus dos variedades, aparece en el espacio público de la CABA. En particular nos enfocaremos en el Barrio Chino. Si bien todo espacio público es un espacio simbólico (Srhir 2013), este en particular cobra una mayor dimensión ya que se propone, a partir de su denominación y de prácticas del GCBA que analizaremos en este apartado, como un "territorio extranjero" dentro de la Ciudad. Además, es un espacio del cual los inmigrantes (taiwaneses, primero y chinos, después) se apropiaron y transformaron. El relevamiento del paisaje lingüístico fue realizado en los meses de febrero y marzo del año 2017. Todas las fotos (excepto la que se indica) fueron tomadas por la autora del artículo. Para tomar las fotos, se realizaron dos visitas al Barrio: una durante un fin de semana, que permitió elegir los lugares a fotografiar, y una durante la semana, día en que se tomaron las fotos. Se eligió hacerlas durante la semana ya que durante los fines de semana es un espacio muy visitado. El recorrido incluyó todas las cuadras del Barrio.

Antes de mostrar el relevamiento hecho sobre ese Barrio, unas palabras sobre los otros espacios de la Ciudad en los que se puede ver la escritura china: los supermercados y regalerías propiedad de migrantes chinos. De acuerdo con la Federación de Supermercadistas Chinos, hay 8900 negocios de este tipo, de los cuales 3500 están en CABA y GBA, es decir, 
según Grimson, Ng, \& Denardi (2016), es posible encontrar un supermercado de este tipo cada dos o tres cuadras ${ }^{5}$. Se trata de comercios autoservicio que ofrecen artículos básicos para el hogar. Los carteles exteriores en muchos casos tienen presencia de la lengua china, aunque no siempre de su escritura: por ejemplo, algunos nombres de supermercado son Mei Lin, Hua Mei, etc. Hay otros supermercados donde aparece en la marquesina no solo el nombre en alfabeto sino también en sinogramas como 龍旺 (Long Wang). Más allá de las marquesinas, en el caso de los supermercados, hay otras marcas externas que ligan ese espacio con un grupo en particular, pero no son lingüísticas. En la mayoría de los casos estos comercios comparten características arquitectónicas, de distribución espacial y de decoración. El espacio de la lengua y de la escritura está reservado a lo privado.

Dentro del supermercado, al lado de la caja, hay un mostrador desde donde el propietario del supermercado puede ver las filmaciones de las cámaras de seguridad. En las paredes que circulan este pequeño espacio se pueden ver anotaciones hechas a mano. En los últimos años, algunas marcas de productos han desarrollado cartelería en chino para el interior de los supermercados, en general, se trata de un calendario que tiene impresa la marca y el teléfono del proveedor. En muchos de los supermercados visitados este calendario había sido regalado por la empresa de cervezas "Brahma". Pese a que quisimos tomar fotos de esto, no logramos que los propietarios del comercio nos permitieran hacerlo. En las regalerías la presencia de la escritura es similar a la de los supermercados.

\subsection{Barrio chino}

El "Barrio Chino" de la Ciudad Autónoma de Buenos Aires no es el lugar donde viven los migrantes, sino que se trata de una zona exclusivamente comercial. Dentro de la comunidad el barrio es denominado Zhong guo cheng [中国城], que se puede traducir como "ciudad o pueblo chino", entendiendo chino como propio del país RPC, o Taiwan jie [台湾街] que se traduce como la "calle de Taiwán". Estas dos denominaciones muestran ya las dos oleadas migratorias y cómo en este espacio se superponen. Es en esta línea en la que analizaremos la presencia de la escritura en este espacio público. Asimismo, en los últimos años el Gobierno de la Ciudad Autónoma de Buenos Aires (GCBA, en adelante) realizó sobre este espacio intervenciones con el objetivo de revalorizarlo como un espacio turístico de la Ciudad. También mostraremos en este apartado de qué manera las modificaciones propuestas por el GCBA modifican el paisaje lingüístico de este Barrio.

Geográficamente, está ubicado junto a la estación de tren "Belgrano C" de la línea Mitre (ramal Tigre) y consta de aproximadamente 6 cuadras. El ingreso es por la calle Arribeños esquina Juramento, donde en el año 2009 se emplazó un arco de bienvenida (al cual nos referiremos más adelante). Está muy cerca de las Barrancas de Belgrano y de la Avenida del Libertador, por lo que hay muchas formas de acceso con transporte público.

En la película Arribeños, estrenada en 2015 y dirigida por Marcos Rodríguez, se narran los inicios de este barrio desde la perspectiva de los migrantes taiwaneses. En la película, se cuenta que la "Calle de Taiwán" era el lugar de encuentro con los compatriotas; muchos de los
5. Es tal la magnitud de esta actividad económica que en varias ciudades del interior del país se intentó restringir la apertura de este tipo de comercios (Eleisegui 2009). 
entrevistados resaltan que allí era donde se podía conseguir la comida taiwanesa y donde se veían películas en chino. En Papier (2011), se analizan los comienzos y transformaciones del barrio a través de entrevistas con diversos actores y referentes de la comunidad (aunque, en general, se restringe a descendientes de taiwaneses). Muchos de los entrevistados asociaron el comienzo del barrio con la fundación en 1972 de la "Asociación Civil de los Chinos de Taiwán en Argentina" ${ }^{6}$ en la calle Arribeños. La asociación aun funciona en el mismo lugar y su marquesina está escrita en sinogramas tradicionales y español. Esta asociación organiza en su sede uno de los festejos del año nuevo chino (para una discusión sobre el tema, Laborde 2017 o Denardi 2017).

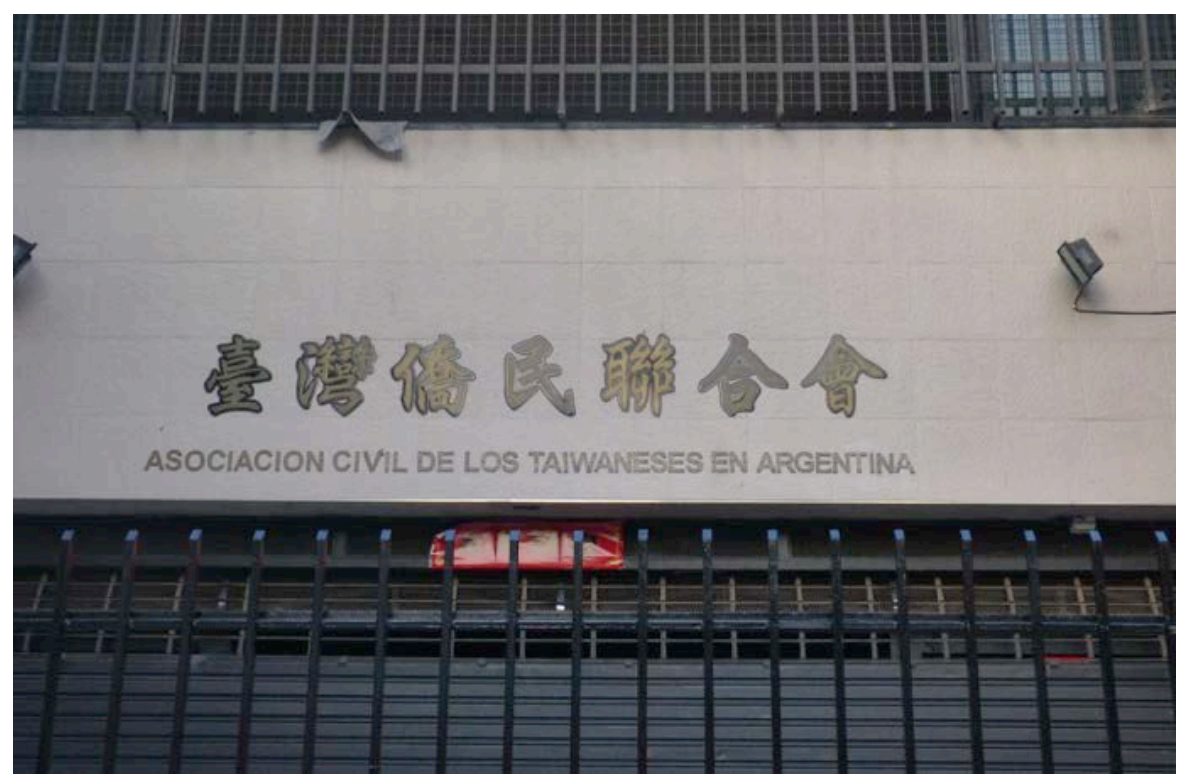

Foto 1. Asociación civil de los taiwaneses en Argentina (foto propia)

Es a partir de la crisis del 2001, y en particular desde el 2004 en adelante, que el barrio deja de ser un lugar de encuentro de la comunidad taiwanesa. Las causas son principalmente dos: por un lado, la crisis económica en Argentina hizo que muchos migrantes taiwaneses decidieran irse de Argentina (algunos volvieron a Taiwán y otros fueron a otros países, entre ellos, Estados Unidos), y por el otro lado, el crecimiento de la migración de la República Popular China a Argentina. Son estos últimos migrantes los que abren locales de venta de artículos importados asociados a la cultura china.

En el Barrio hay presencia tanto de escritura tradicional como de la simplificada. También, pero en menor proporción se utiliza la escritura alfabética para escribir español o inglés. Por ejemplo, en el año 2011, se estrenó la película de Disney Kung Fu Panda 2. La versión original de la película es en lengua inglesa pero el protagonista es un panda que practica kung fu y vive en China. Antes de su estreno, hubo en la entrada del Barrio Chino un cartel en el cual se publicitaba que en un cine cercano se iba a proyectar la película en mandarín. El cartel estaba escrito utilizando sinogramas simplificados y solo se traducía al español la información sobre el lugar y cómo era la copia que presentaban.
6. Para más información sobre las funciones e historia de esta asociación y otras en Argentina, consultar Grimson, Ng \& Denardi: 2016. 


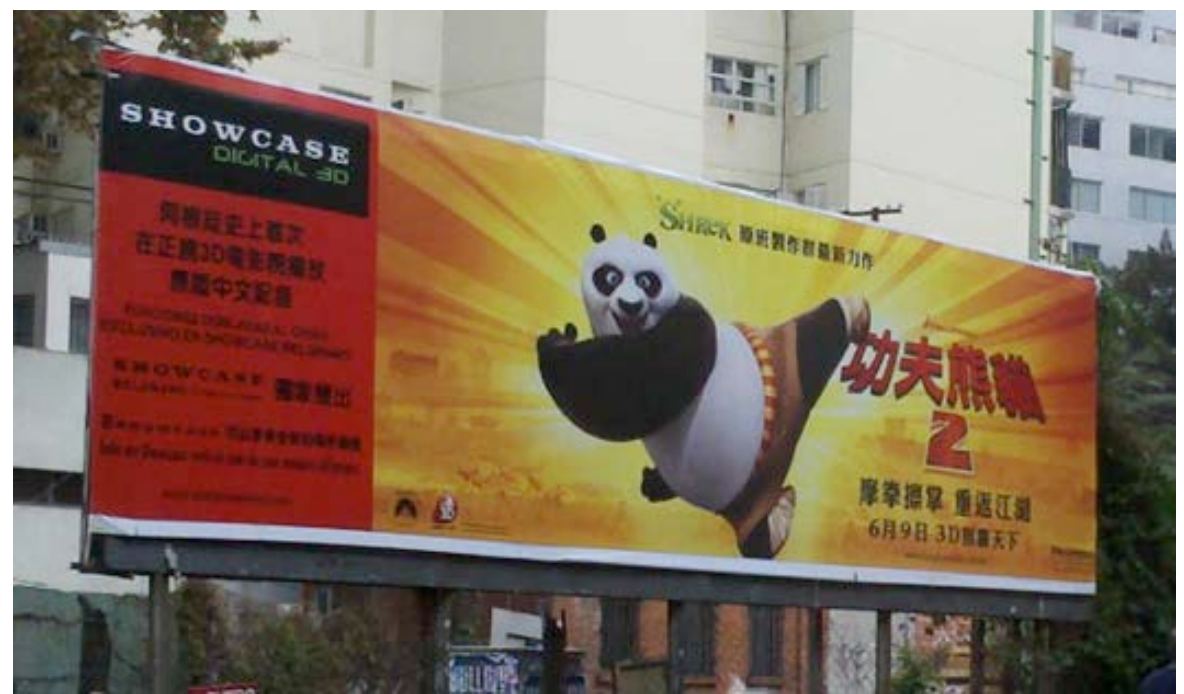

Foto 2. "Kunfu Panda 3" afiche en el Barrio Chino (foto publicada en Caruso 2011)

La mayoría de los locales ubicados sobre Arribeños y sus perpendiculares tiene un fin comercial. Muchos de ellos son regalerías en las que se venden diversos artículos importados de China que, en general, remiten a este país: abanicos de papel, juego de pinceles y tinta para hacer caligrafía, camisolas o vestidos típicos, adornos para el hogar con la forma de los animales del horóscopo o con peces. Sobre las calles perpendiculares hay dos supermercados, Ichiban y Asia Oriental, en donde se pueden comprar comidas chinas, condimentos y fideos importados, bolsones de arroz y pescado, entre otros. A partir de la cartelería en estos supermercados, se puede inferir que el público es principalmente hablante de chino.

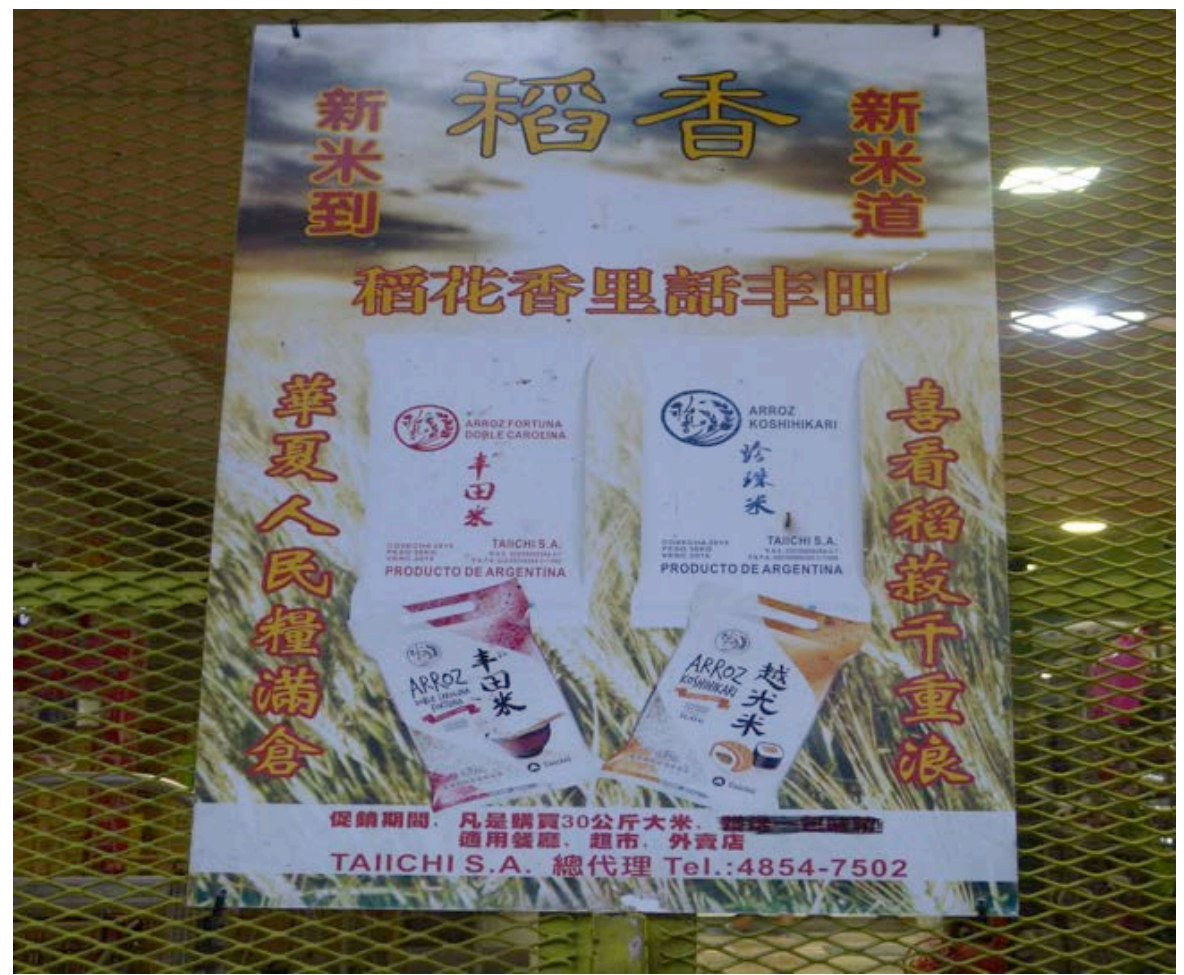

Foto 3. Anuncio de venta de bolsones de arroz en un supermercado (foto propia) 
Además, hay dos almacenes más pequeños: Casa China, que está en el Barrio desde sus comienzos, y Tina \& Co., que abrió en el 2015; ambos negocios venden productos gastronómicos "gourmet". Tina \& Co. cuenta, además, con una cafetería (rubro que no había en el barrio). Finalmente, hay varios locales gastronómicos principalmente de comida china. En los últimos años, aparecieron restaurantes de comida japonesa, tailandesa y uno que se presenta como comida taiwanesa, marcando una diferenciación con los otros restaurantes de comida de la zona.

La cartelería de los locales del barrio está escrita, principalmente, en chino, aunque fluctúa entre la escritura tradicional y la simplificada. Por ejemplo, en los carteles de estos dos salones de belleza podemos ver que en el primero el cartel está escrito en caracteres tradicionales y en español y en el segundo caso, solamente se utiliza la escritura simplificada. Entendemos que esta diferencia se relaciona con las distintas oleadas migratorias a Argentina: la taiwanesa, primero, y la proveniente desde la RPC en los últimos años.
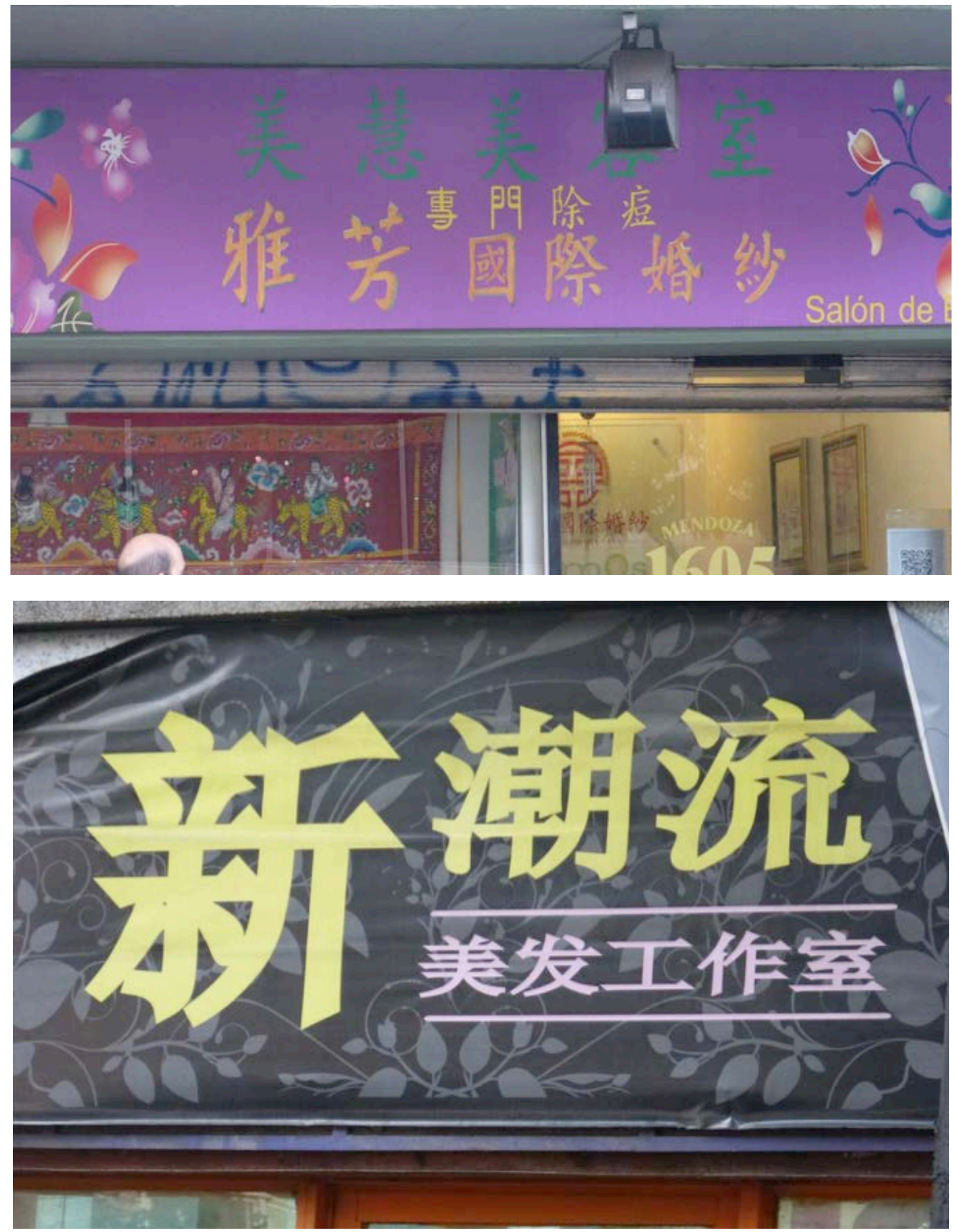

Fotos 4 y 5 . Salones de belleza en el Barrio Chino (fotos propias) 
En los ejemplos hasta aquí referidos parece que las dos escrituras conviven en el mismo espacio público y que la utilización de una u otro remite exclusivamente a las distintas oleadas migratorias. Sin embargo, analizar las fachadas de dos instituciones religiosas del Barrio, en la cual figuran las dos variedades escriturarias, permite mostrar de qué manera los dos grupos migrantes se superponen en el espacio público, no siempre con el mismo valor.

Sobre la calle Mendoza, funciona la Iglesia Presbiteriana Sin-Heng Nuevo Avivamiento, que ofrece culto en diferentes horarios en taiwanés, en español y en chino mandarín.

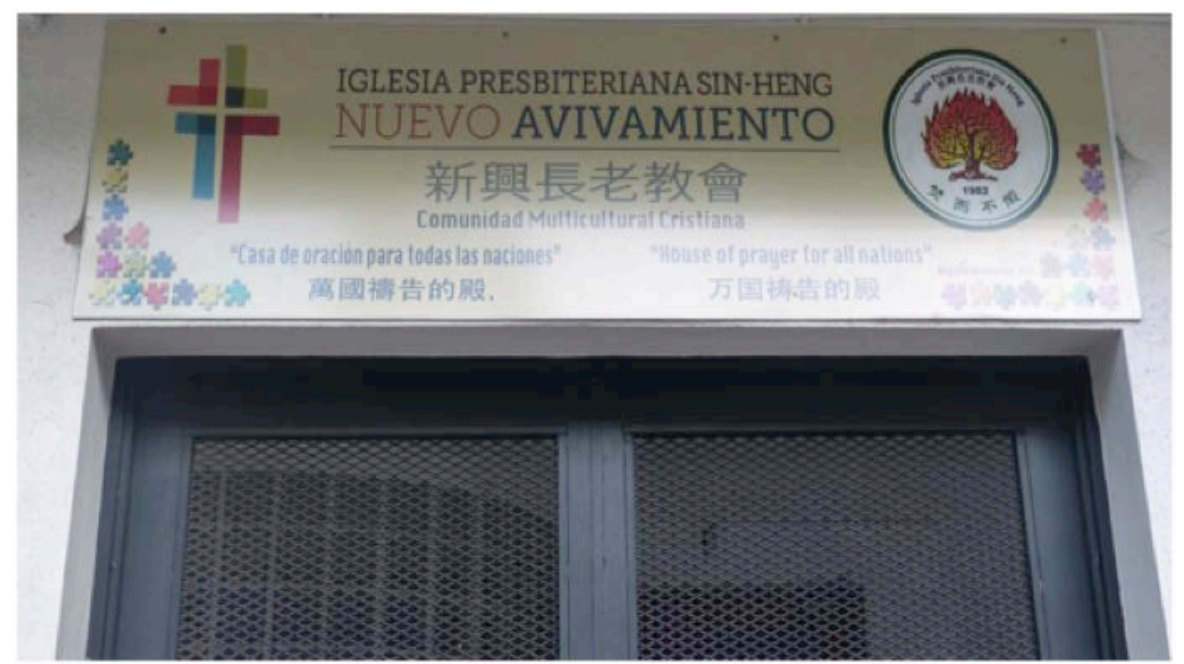

Foto 6. Iglesia Presbiteriana del Barrio Chino (foto propia)

Tal como se ve en la foto, en el cartel de la iglesia están presentes el español, el inglés y la escritura tradicional y la simplificada del chino. Sin embargo, tienen distinta jerarquía. El nombre de la iglesia está tanto en español como en sinogramas tradicionales, pero no en simplificados; la aclaración "Comunidad Multicultural Cristiana" figura solo en español. Más abajo a la derecha, "Casa de oración para todas las naciones" figura en español y abajo en chino tradicional, hacia la derecha en inglés y debajo en simplificado. Es decir, la lengua española y la escritura tradicional poseen una jerarquía similar, mientras que la escritura simplificada se utiliza como traducción de la "lengua extranjera", el inglés. Los anuncios que están pegados sobre las rejas en los que se indican los horarios de los cultos y de las oficinas están en español y en tradicional. En este caso, desaparecen tanto el inglés como la escritura simplificada, lo cual reafirma la idea de que estas dos últimas lenguas tienen un lugar menor en la Institución. La escritura simplificada es solamente una escritura más en el anuncio y con un peso similar al que tiene el inglés. 

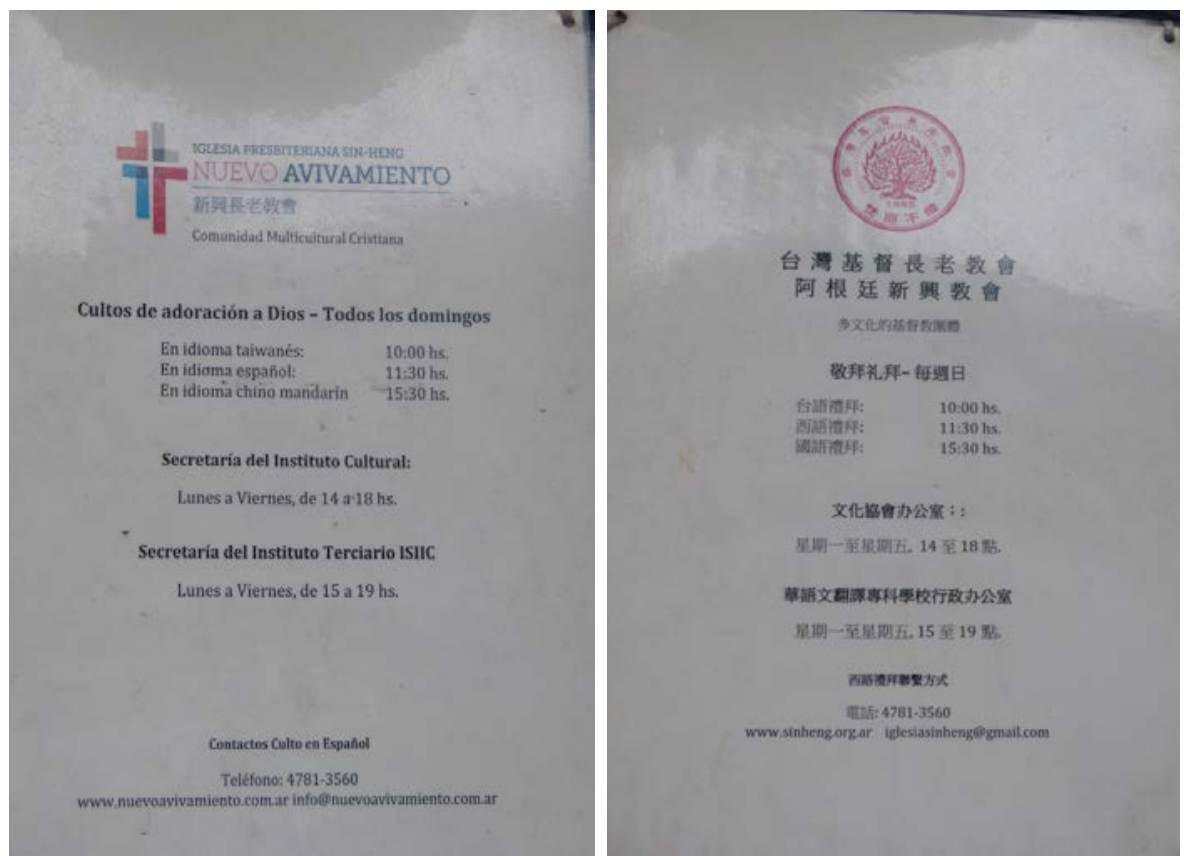

Fotos 7 y 8 . Anuncios en la Iglesia Presbiteriana del Barrio Chino (fotos propias)

El templo budista Tzon Kuan en la calle Montañeses no solo es un lugar religioso sino también de difusión de la cultura: en este espacio se dictan clases de kung-fu y de meditación abiertas a la comunidad. Además, en este espacio funciona, los días sábados, una escuela en la cual los descendientes de migrantes estudian mandarín 7 .

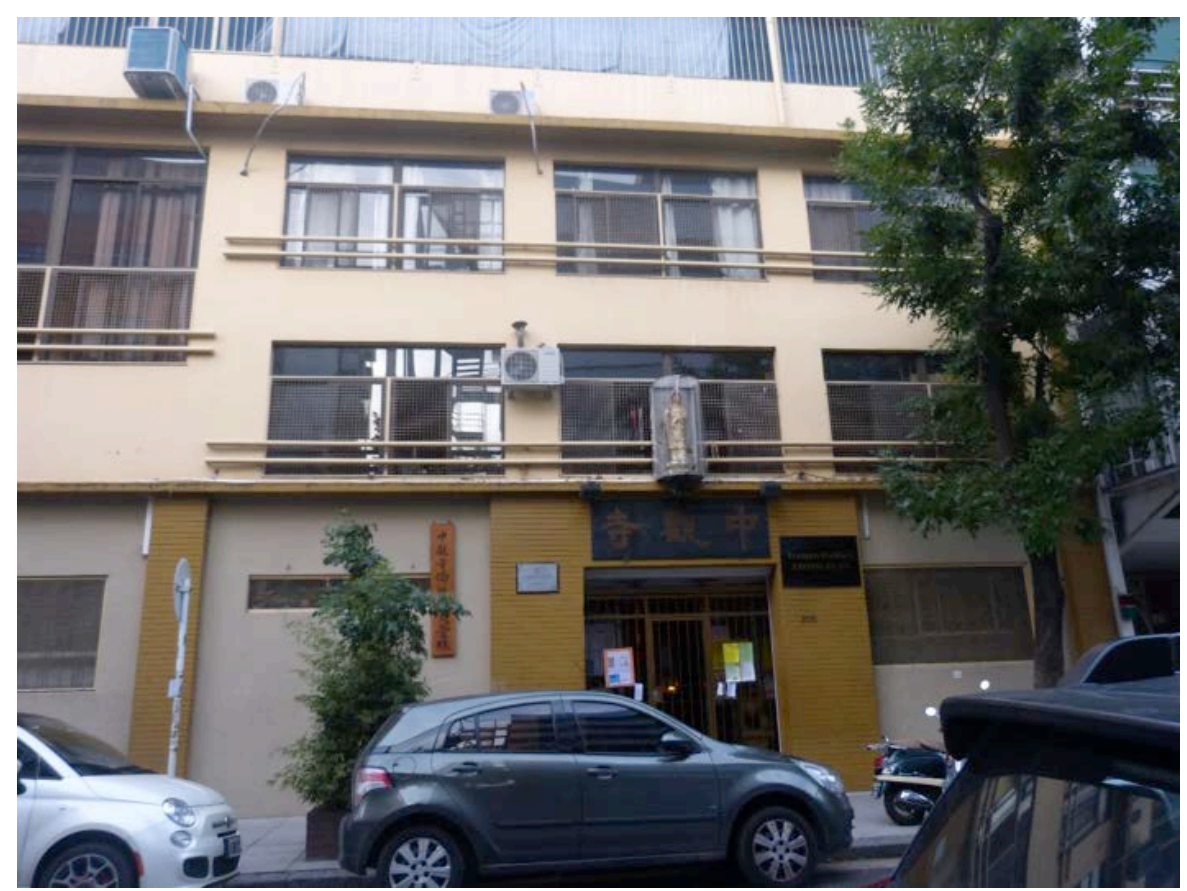
sobra la enseñanza de chino en este lugar, puede leerse Sartori 2017

Foto 9. Puerta de entrada del Templo Budista Tzon Kuang (foto propia)

En la fachada del templo se puede apreciar la convivencia de los tres sistemas de escritura del Barrio: la escritura china tradicional, la simplificada 
y, por último, el sistema alfabético. La escritura tradicional es la que se utiliza tanto en el nombre del templo (foto 11) como en el cartel de madera dispuesto en vertical.

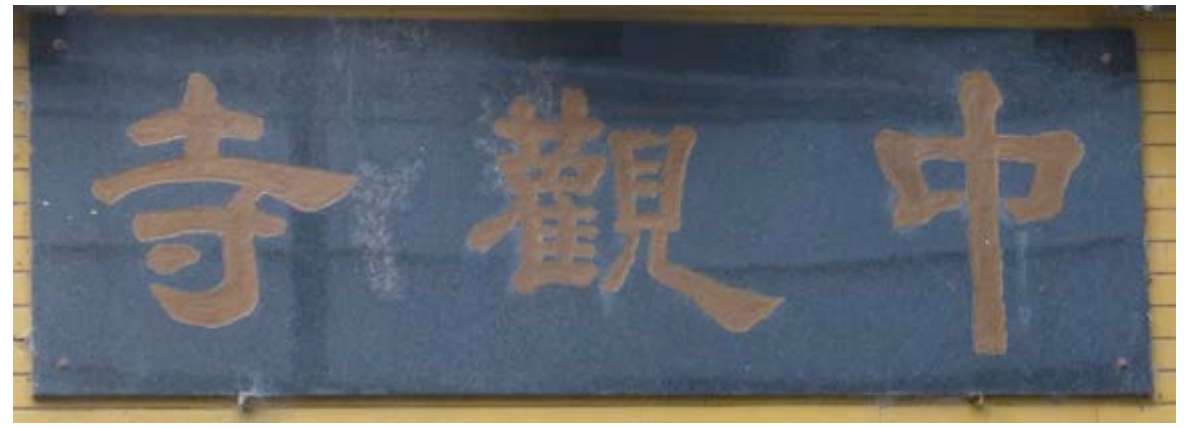

Foto 10. Nombre del templo (foto propia)

La escritura simplificada del chino aparece en la placa metálica ubicada a la derecha de la puerta. En letra caligráfica se puede leer 口文教育示范学校 [huawen jiaoyu shifan xuexiao, escuela ejemplar de enseñanza de lengua china]. La oficina que otorga esta placa (en letra de molde) es 中口人民共 和国国口院口吅公室 [zhonghua renmin gongheguo guowuyuan qiaowu bangongshi, la Oficina de Asuntos de los Chinos de Ultramar de la República Popular China]. Es decir, se trata de una placa otorgada por una oficina del gobierno de la República Popular China que está ubicada en un templo que, anteriormente, se asociaba con la comunidad taiwanesa.

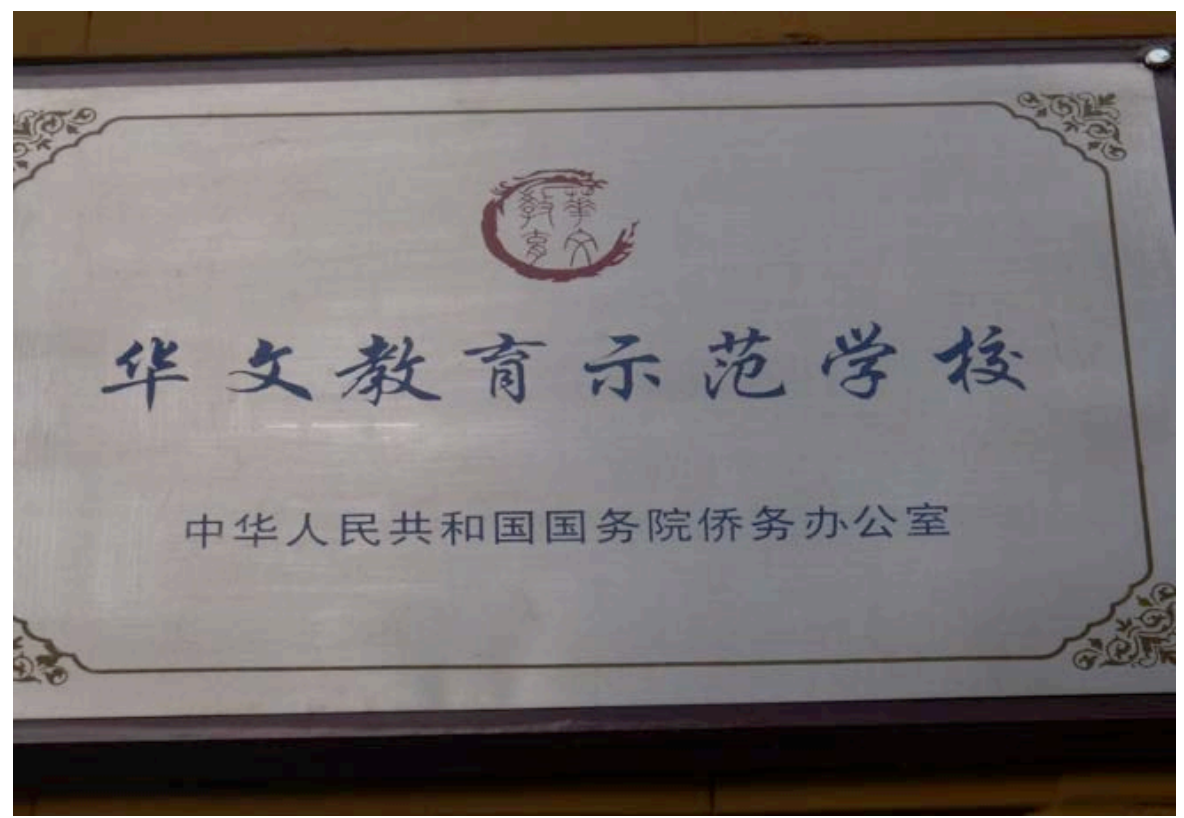

Foto 11. Placa en la escuela el Templo Budista (foto propia)

Por último, la escritura alfabética (y también la escritura simplificada) aparece en los anuncios que están pegados en la puerta del Templo. Las distintas actividades que promocionan se imparten en español, por esa razón, entendemos el anuncio está escrito principalmente en español. 


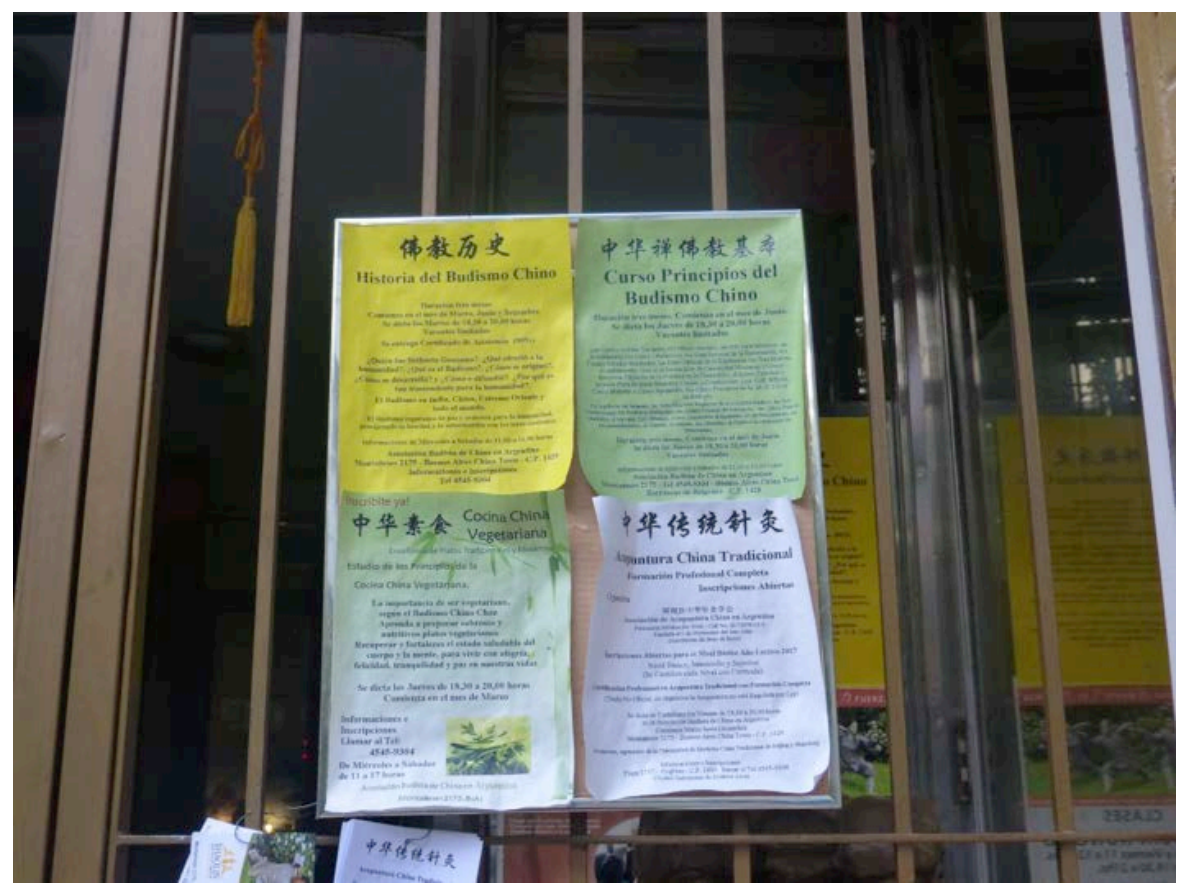

Foto 12. Cartelería en la puerta del Templo Tzong Kuang (foto propia).

Para poder entender la superposición de sinogramas tradicionales y simplificados en el frente de este templo, es necesario tener en cuenta lo que ya mencionamos anteriormente de las distintas oleadas migratorias. En este Templo, como ya dijimos, funciona una escuela los días sábados. A esta escuela, tanto Vetter (2011) como Zuzek (2004), la relacionan con los inmigrantes taiwaneses. Zuzek sostiene que los profesores de esa institución reciben la visita de expertos de Taiwán que los capacitan. Asimismo, Vetter afirma que "Otra característica especial es la administración, porque la Escuela Qiaolian es parte de las Comisiones de Asuntos de Compatriotas de Ultramar del Gobierno de Taiwán. Es la única escuela de gobierno estatal en Buenos Aires." Sin embargo, el año en que tomamos las fotos, ya no se relacionaba con los migrantes taiwaneses sino con los de la RPC y no recibía apoyo de Taiwán sino de la Oficina para los Asuntos de los Chinos de Ultramar, que depende de la RPC (esta afiliación se ve claramente al observar la placa a la que nos referimos previamente, foto 12). El 15 de junio del 2014 en la página web de esta Oficina ${ }^{8}$, publicaron una nota que refiere a la instalación de esta placa en el marco de una visita del Jefe adjunto de la Oficina de asuntos chinos de ultramar del Consejo de Estado de China al Barrio Chino de la CABA. Según la nota, esta visita se debe a la intención de este funcionario de "visitar y saludar a los compatriotas chinos de ultramar". Es decir, entre el año 2011 (en el que Vetter realizó su investigación) y 2014, la escuela dejó de relacionarse con los taiwaneses y pasó a estar relacionada con los migrantes de la RPC e, incluso, fue reconocida por el Estado chino. Se puede ver en este frente en particular las distintas intervenciones sobre el espacio público hechas por dos agentes: los inmigrantes y, en este caso en particular, el Estado de la RPC. Al comienzo de este artículo, nos preguntábamos quiénes podían intervenir sobre el paisaje lingüístico de este Barrio. En esta fachada se puede ver que no solo son los inmigrantes los que definen qué se escribe en el Barrio sino también la RPC.

8. La nota se encuentra en este link: http://www.gqb.gov.cn/ news/2014/0615/33247.shtml La traducción de las palabras del Jefe Adjunto es propia. 
En 2009, en el marco de las transformaciones que se hicieron sobre el espacio público del Barrio Chino se instaló un arco de bienvenida ${ }^{9}$. Laborde (2011) afirma que el arco fue donado por empresarios chinos argentinos a la Ciudad. Sin embargo, otras versiones dicen que fue donado por el Gobierno de la RPC. La prensa argentina recoge este rumor y lo afirma diciendo que "el gobierno de China desembolsó alrededor de medio millón de dólares" y que entre los obreros que instalaron el arco también había ciudadanos chinos que viajaron exclusivamente para el emplazamiento del arco (La Nación 23/05/2009). El emplazamiento del arco no estuvo exento de polémica, Denardi (2017) da cuenta de ella. Por un lado, los residentes no chinos temen que el barrio se convierta en un espacio netamente comercial. Por otro lado, los distintos referentes y comerciantes de la zona analizaron la instalación del arco de distinta manera: algunos de los consultantes taiwaneses de Denardi vieron en la instalación del arco una invasión de República Popular China; otros, en cambio, vieron en esto la posibilidad de equipararse con los otros barrios chinos del mundo y, como consecuencia de esto, de aumentar la cantidad de visitantes y, con ello, las ventas. La misma nota de La Nación a la que referíamos más arriba también recoge las opiniones sobre la instalación del arco de la Asociación Vecinal de Fomento del Barrio Parque General Belgrano quienes sostienen que si bien se aceptan donaciones de países extranjeras, estas deben ser ubicadas en plazas y paseos sin fijar territorialidad; es decir, se niegan a que el sector comercial quede asociado a un grupo en particular.

Además, del emplazamiento del arco, se peatonalizó la zona y se instalaron dragones. Es en estos años que el GCBA empieza, además, a ofrecerlo como un destino turístico en su página web. Según Laborde (2017), la construcción del Barrio y su carga de identidad se estableció fuertemente a partir del refuerzo de la tipificación y el estereotipo del inmigrante y de lo oriental. La instalación del arco es analizada por la autora en relación con este proceso.

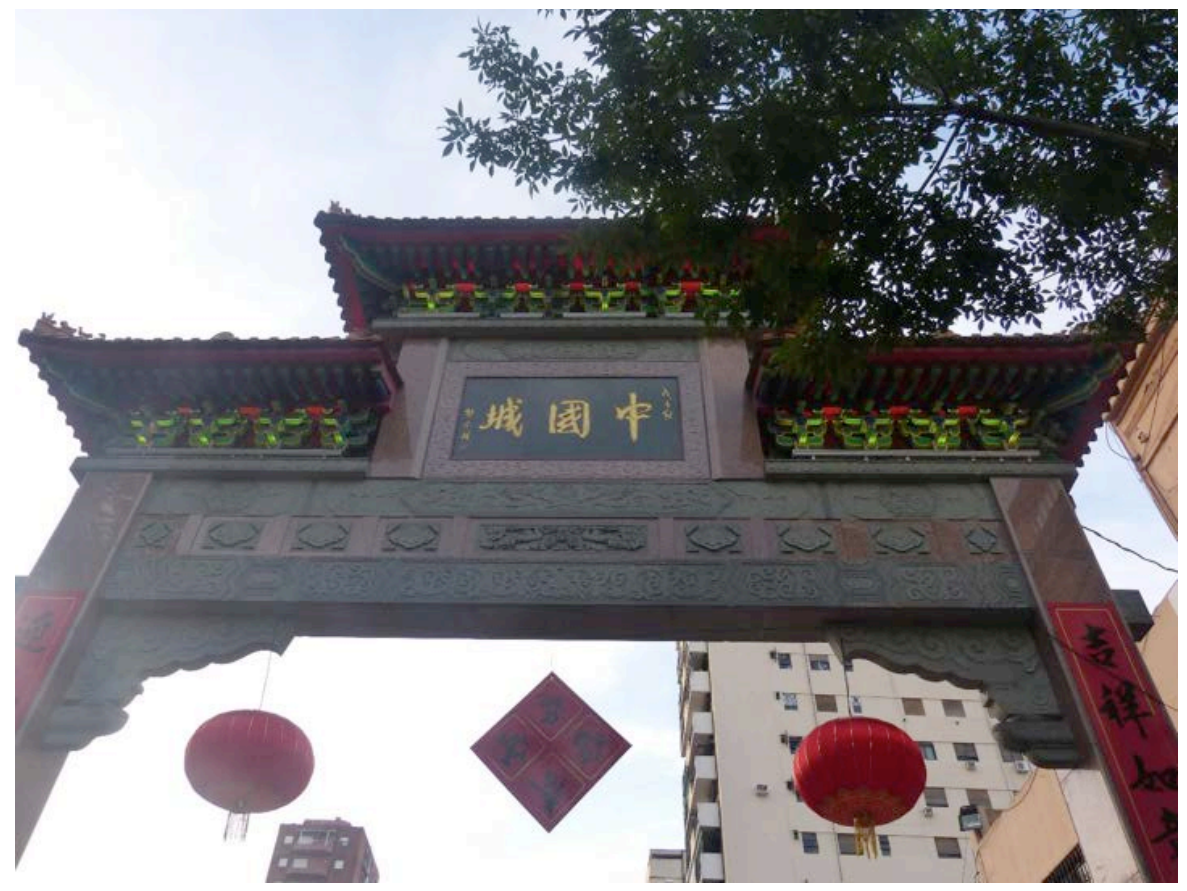

Foto 13. Arco del Barrio Chino de la CABA (foto propia).
9. Sobre la calle Arribeños casi esquina Juramento. El arco es visible desde la estación de tren. 
La inscripción en dorado sobre el arco dice 中国城, es decir, Barrio Chino. Está escrito en sinogramas tradicionales y de derecha a izquierda. En este caso en particular, la elección de la escritura tradicional no se debe a una adscripción a Taiwán ya que en República Popular China también se escribe con esta grafía sobre los arcos y monumentos históricos (la Ley de Lenguas del año 2001 legisla al respecto). A los costados del arco, escrito en negro sobre un paño rojo hay dísticos que se colocan en año nuevo en todas las casas para ahuyentar a los malos espíritus y traer prosperidad al hogar.

En 2016, se cambió la señalética del Barrio por carteles en los que se indica el nombre de la calle no solo en español sino también en putonghua. Si bien la escritura elegida para hacer la traducción de los nombres españoles fue la simplificada, en el nombre de la calle Arribeños uno de los sinogramas utilizados es el tradicional y no el simplificado: se utiliza 紐 en lugar de $\square$.

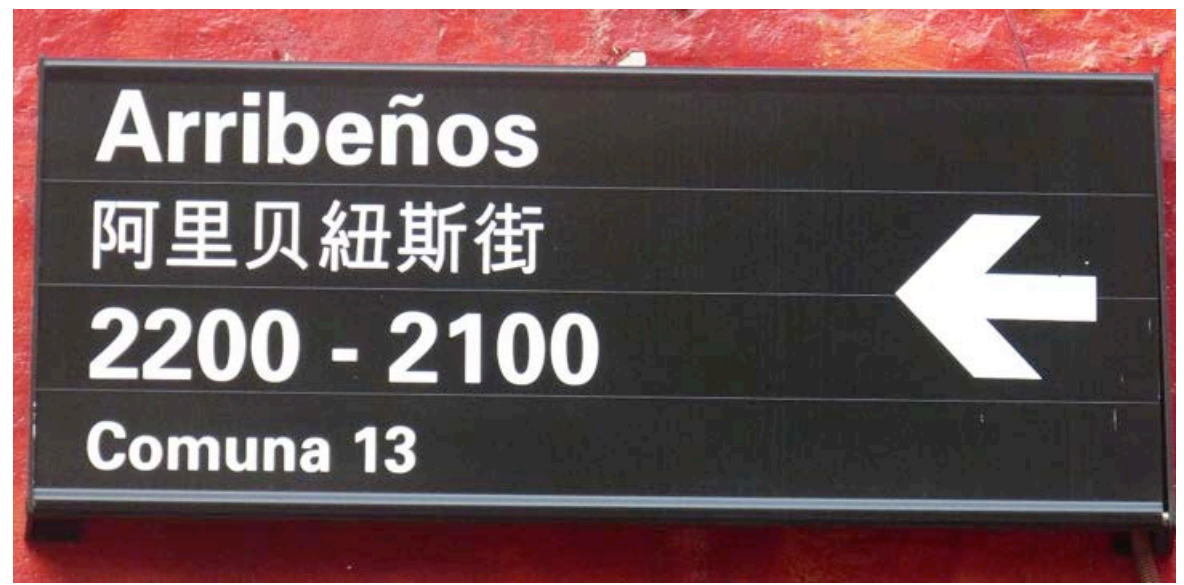

Foto 14. Señalética en el Barrio Chino (foto propia).

El cambio de la señalética, junto con la peatonalización de la zona, muestra una clara intervención del Estado municipal sobre el espacio público y el paisaje lingüístico. Es interesante resaltar que la etnización de la cual habla Laborde se lleva a cabo no solo en la ubicación de elementos que remiten a la cultura china, dragones y arco, sino en el emplazamiento de carteles escritos en lengua china. La escritura, entendemos, se convierte en un elemento más que contribuye a la construcción de un otro étnica y lingüísticamente marcado. Que la señalética bilingüe se haya puesto solo en las seis calles que constituyen la zona comercial y no en su cercanía permite inferir que se busca construir una escenografía y no aportar a que aquellos que no pueden leer los nombres en español se ubiquen dentro del barrio y para llegar a él, es decir, la función de esta señalética no es instrumental. Las notas de prensa que dan cuenta de esta decisión retoman las palabras de Eduardo Macchiavelli, ministro de ambiente y espacio público del Gobierno de la Ciudad Autónoma de Buenos Aires:

A partir de ahora, los vecinos que visiten el barrio chino podrán leer el nombre de las calles en ambos idiomas. De esta manera contribuimos a mantener la identidad del barrio, a fomentar la convergencia de ambas culturas y a mejorar el ordenamiento y la movilidad en el espacio público (Clarín 19/o8/2016, versión digital).

El carácter turístico del lugar y de la elección de esa señalética queda claro en el verbo "visitar": no se dirige a aquellos que habitan o trabajan 
ahí sino a los que, siendo vecinos de la CABA, visitan el Barrio. Por último, el ministro hace hincapié en que esta medida mejoraría el ordenamiento y la movilidad en el espacio público. A diferencia de esta afirmación, en la sección de noticias de la página del Gobierno de la Ciudad se dice que la finalidad de la nueva señalética es: "seguir resaltando las virtudes que ya tiene la calle Arribeños y su entorno", cabe preguntarse cuáles son las virtudes que ya tiene la calle Arribeños que la utilización del chino resalta.

\section{Conclusiones}

Al comienzo de este artículo mostramos cómo en los últimos años la lengua china comenzó a tener mayor presencia en Argentina. En particular, nos referimos a la enseñanza de esta lengua y las representaciones sobre las que se sostiene ("la lengua del futuro"). Mostramos, brevemente, qué instituciones la enseñan lo cual los permitió reconocer tres agentes: los inmigrantes - chinos y taiwaneses-, el Estado municipal y el Gobierno Chino. Con la hipótesis de que iba a ser posible reconocer estos agentes también en el caso de la presencia de la escritura china en el paisaje lingüístico de la CABA, relevamos el paisaje lingüístico del Barrio Chino de esta Ciudad. La elección de este espacio geográfico estuvo motivada por la importancia simbólica que tiene.

Como primera conclusión, es posible sostener que en Barrio se pueden reconocer las dos escrituras chinas, la tradicional y la simplificada, y que el uso de una y otra se relaciona con los dos momentos de las migraciones chinas que mostramos. En este sentido, sostenemos que no es posible interpretar el paisaje lingüístico de una zona atendiendo exclusivamente a la dimensión sincrónica: el hecho de poder historizar el lugar y sus escrituras aporta una nueva dimensión significativa de análisis. También es posible reconocer la manera en la que estos dos momentos migratorios se superponen y disputan espacios. Estas tensiones y distancias quedan visibles, por ejemplo, en el caso de la Iglesia Presbiteriana, que coloca la escritura simplificada en el mismo lugar que el inglés, es decir, el lugar de una lengua extranjera. Asimismo, la fachada del templo Tzong Kuang muestra la intrusión del Estado chino en el espacio público del Barrio, así como las distintas capas de migración.

Como segunda conclusión, es posible ver en este espacio público la función del GCBA que también contribuye a la conformación del paisaje lingüístico del Barrio. El GCBA, por su parte, elige la escritura simplificada para realizar la señalética del Barrio, tomando de esta manera una posición también política respecto de cuál es la escritura asociada a los "chinos". Finalmente, como ya dijimos, esta intervención sobre el espacio público utiliza la escritura no con un fin instrumental sino para construir un escenario en el cual la "cultura china" es ofrecida al "turista".

En esta línea, el artículo de Heller, Pujolar y Duchenê (2014) permite pensar en los modos en los que el turismo se relaciona con el hecho de entender las lenguas como un commodity. En este caso en particular, la escritura china permite configurar un escenario en el que lo exótico y lo distinto es puesto en primer lugar para mostrarle al porteño que visita el Barrio que puede ser "turista" en su propia ciudad. A su vez, esta escritura pone a la vista de todos los porteños el carácter de mosaico multicultural de la Ciudad (Laborde 2017). En este sentido, la escritura china representa la 
diversidad presente en la Ciudad. A pesar de esto, el Estado municipal, al asociar escritura con una única cultura e identidad, la china, deja por fuera de toda discusión la heterogeneidad y los conflictos existentes entre los distintos inmigrantes. Resta por analizar si esta misma commodificación de la escritura ocurre en relación con la lengua china, no ya con la escritura, en espacio de la Ciudad Autónoma de Buenos Aires. 


\section{Q Bibliografía}

"Caruso, Ana Laura. 2011. “El panda también le habla al "Barrio Chino»". Diario Perfil, 16 de junio. Fecha de consulta, o6/o9/2017. http://www.perfil.com/espectaculos/El-pandatambien-le-habla-al-Barrio-Chino-20110616-0033.html

"Clarín. 2016. “Literal: en Belgrano, ahora los carteles de las calles están en chino". Diario Clarín, 19 de agosto. Fecha de consulta, 06/09/2017. http://www.clarin.com/ciudades/ literal-belgrano-carteles-calles-chino_o_rkS289Vc.html

»Delmonte, R., Denardi, L., \& Sartori, M. F. 2018. “Migración china en buenos aires: más allá de los supermercados". Revista Márgenes. http://www.unsam.edu.ar/margenes/ migracion-china/

"Denardi, Luciana. 2016. “Casetes, redes y banquetes. Prácticas comerciales de chinos, taiwaneses y argentinos en Buenos Aires" Etnografias Contemporáneas 2 (2):134-160.

"Denardi, Luciana. 2017. "Migraciones chinas y taiwanesas en Buenos Aires: Estado, organizaciones y rituales". Tesis de doctorado. IDAES -Universidad Nacional de San Martín

»Eleisegui, Patricio. 2009. "En el país se levanta una "muralla" para frenar a los supermercados chinos". IProfesional, 30 de octubre. Fecha de consulta, 12/06/2019. https:// www.iprofesional.com/notas/88956-En-el-pais-se-levanta-una-muralla-para-frenara-los-supermercados-chinos

》 Gobierno de la Ciudad de Buenos Aires, 2016. http://www.buenosaires.gob.ar/noticias/ nuevos-carteles-bilingues-en-el-barrio-chino

" Grimson, Alejandro; Ng, Gustavo y Denardi, Luciana. 2016. "Las organizaciones de inmigrantes chinos en Argentina” Migración y Desarrollo, vol. 14, núm. 26: 25-73.

" Heller, Mónica; Pujolar, Joan y Duchenê, Alexandre.2014. "Linguistic commodification in tourism". J Sociolinguistics, 18: 539-566. doi:10.1111/josl.12082

» Instituto Nacional de Estadísticas y Censos. 2010. Censo Nacional de Población. 2010. Fecha de consulta, o6/og/2017 http://www.indec.gov.ar/nivel4_default.asp?id_ tema_1=2\&id_tema_2=41\&id_tema_3=135

» Laborde, María Soledad. 2008. “Apropiación y disputa en la conformación del «Barrio Chino" en la Ciudad de Buenos Aires: el patrimonio inmaterial como estrategia”. Trabajo presentado en IX Congreso Argentino de Antropología Social. Facultad de Humanidades y Ciencias Sociales. Universidad Nacional de Misiones, Posadas, 2008. Disponible en línea: <http://cdsa.aacademica.org/ooo-08o/111.pdf> Fecha de consulta, 03/08/2017

" Laborde, Soledad. 2017. "La ciudad a través de la etnicidad habitada. Negociaciones socioculturales en torno a "lo afro", "lo chino" y «lo boliviano" en los procesos de recualificación y relegación urbana de la ciudad de Buenos Aires". Tesis de doctorado, Universidad de Buenos Aires.

" La Nación. 2009. “Construyen un arco en el Barrio Chino”. La Nación, 23 de mayo. Fecha de consulta, 12/06/2019. https://www.lanacion.com.ar/sociedad/construyen-un-arcoen-el-barrio-chino-nid1131379

"Lien Tan-Pan. 2005. “La reforma de la escritura china: la simplificación” Estudios de Asia y África, XL: 2.

" Manzoni, Carlos. 2011. "Los Súper chinos crecen en el interior”. La Nación, 30 de enero. Fecha de consulta, 03/03/2017 http://www.lanacion.com.ar/1345462-los-super-chinoscrecen-en-el-interior\#comunidad 
» Papier, Andrea. 2011. “Inmigración china en Argentina: el barrio chino de Bs As como caso de estudio intercultural”. Trabajo presentado en XIII Congreso Internacional de ALADAA, Disponible en línea: <http://ceaa.colmex.mx/aladaa/memoria_xiii_congreso_internacional/images/pappier.pdf> Fecha de consulta: 03/03/2017

» Rohsenow, J. S. 2004. “The genesis of the language law of 2001”. En Language Policy in the People's Republic of China. Theory and Practice since 1949, editado por Zhou Minglang \& Hongkai Sun, 21-44. Boston: Springer Netherlands.

» Rovira Esteva, Sara. 2010. Lengua y escritura china. Mitos y realidades. Barcelona: Ediciones Bellaterra.

»Sartori, María Florencia. 2017. "Propuestas educativas para migrantes chinos en la Ciudad de Buenos Aires”. Jornadas. Un siglo de migraciones en la Argentina contemporánea (1914-2014) compilado por Nadia de Cristóforis y Susana Novick. Buenos Aires, Instituto de Investigaciones Gino Germani, Universidad de Buenos Aires: 931 - 942.

»Shohamy, Elena. 2015. “LL research as expanding language and language policy”. Linguistic Landscape Vol. 1:1/2: 152-171.

»Srhir, Adil.2013. “Nueva economía y dinámicas de cambio sociolingüístico en el paisaje lingüístico de Madrid: El caso del árabe”. Revista Internacional De Lingüística Iberoamericana, 11(1(21)): 89-108.

»Vetter, Dirk. 2011. Das Spanisch der Chinesen in Buenos Aires: Lernersprachliche Strategien und narrative Identität. Universidad de Freiburg. Disponible en línea: http://www.freidok. uni-freiburg.de/volltexte/8534 Fecha de consulta, 12/06/2019.

»Zukek, Cristina. 2004. "Identidad y aculturación: el caso de los inmigrantes taiwaneses jóvenes.” Disponible en línea: http://racimo.usal.edu.ar/112/1/Zuzek1.pdf Fecha de consulta, 05/08/2014.

\section{Páginas web de las instituciones}

»Asociación Cultural Chino Argentina: http://www.chinoargentina.org.ar/

»Escuela Chino Argentina: http://www.escuelachina.com.ar/index.html

» Instituto Confucio de Buenos Aires: http://www.institutoconfucio.edu.ar/

» Instituto Cultural SinHeng: http://www.institutosinheng.com/sin-heng.html

» Laboratorio de Idiomas de la Facultad de Filosofía y Letras (UBA): http://idiomas.filo. uba.ar/

» Programa Lenguas en los Barrios: http://www.buenosaires.gob.ar/educacion/idiomas/ lengua-en-los-barrios 